\title{
Indicator Approach to Assessing Climate Change Vulnerability of Communities in Kenya: A Case Study of Kitui County
}

\author{
Mary Mwangi', Evans Kituyi², Gilbert Ouma3, Denis Macharia ${ }^{4}$ \\ ${ }^{1}$ South Eastern Kenya University, Kitui, Kenya \\ ${ }^{2}$ East Africa Institute, Aga Khan University, Nairobi, Kenya \\ ${ }^{3}$ Institute of Climate Change and Adaptation, Nairobi, Kenya \\ ${ }^{4}$ Regional Center for Mapping of Resources for Development, Nairobi, Kenya \\ Email: marylynke@gmail.com
}

How to cite this paper: Mwangi, M., Kituyi, E., Ouma, G., \& Macharia, D. (2020). Indicator Approach to Assessing Climate Change Vulnerability of Communities in Kenya: A Case Study of Kitui County. American Journal of Climate Change, 9, 53-67. https://doi.org/10.4236/ajcc.2020.92005

Received: February 6, 2020

Accepted: April 17, 2020

Published: April 20, 2020

Copyright ( 2020 by author(s) and Scientific Research Publishing Inc. This work is licensed under the Creative Commons Attribution International License (CC BY 4.0).

http://creativecommons.org/licenses/by/4.0/

(c) (i) Open Access

\begin{abstract}
Community vulnerability to climate change can be conceptualized as an aggregate of three vulnerability components: exposure to climatic stress, sensitivity to climate stress and adaptive capacity. However, even within similar regions these vulnerability components are spatially differentiated necessitating the understanding of a regions vulnerability pattern before targeting adaptation assistance. This research sought to understand the differentiated vulnerability patterns of communities in Kitui County as well as the existing coping strategies to guide implementation of adaptation assistance. Indicator approach to vulnerability assessment and focus group discussions were used to understand the vulnerability pattern and coping strategies respectively. Results showed a differentiated vulnerability pattern with a west to east gradient across Kitui County. The pattern exhibited less vulnerability scores on the western and central parts and more vulnerability scores on the eastern and northern parts of the County. Existing coping strategies have become inadequate with increasing climate variability, severity and frequency of extreme climate events, which render the communities even more vulnerable. The patterns of vulnerability can guide appropriate targeting of adaptation assistance and in turn lead to improved climate change resilience and community livelihoods.
\end{abstract}

\section{Keywords}

Climate Change, Exposure, Sensitivity, Adaptive Capacity, Vulnerability

\section{Introduction}

Vulnerability can be defined differently from different perspectives. The fifth as- 
sessment report (AR5) of the Intergovernmental Panel on Climate Change (IPCC) defines vulnerability to climate change as the "degree to which biological, geophysical and socio-economic systems are susceptible to and unable to cope with adverse impacts of climate change including variability and climate related extremes" (IPCC, 2014). The IPCC definition of vulnerability is the most often used framework. This framework recognizes that the susceptibility for harm is not only defined by a stressor but also by a system's sensitivity and its capacity to cope with losses or resist impact (Shirley et al., 2012; Mechler \& Bouwer, 2015). It also separates vulnerability to climate stressors into three components: exposure, sensitivity and adaptive capacity of the system being exposed (Parry et al., 2007).

Coulibaly et al. (2015) defines exposure "as the extent to which a system is exposed to climatic hazard". It may be represented as either long-term climatic changes or changes in climate variability including both magnitude and frequency of extreme events (O'Brien et al., 2004). Sensitivity on the other hand is the "system's condition that can reduce or worsen the impact (ibid) and may be influenced by the characteristics of a system" (IPCC, 2001). In other words, sensitivity is the responsiveness (either positively or negatively) of a system to climatic stimuli. The third parameter is adaptive capacity, which represents the capacity of a system to adjust to the changing climate in order to reduce potential dangers and take advantage of associated opportunities (IPCC, 2014). Moser (1998) links adaptive capacity to asset ownership meaning that the more a person has the higher the adaptive capacity.

Going by the IPCC definition of vulnerability, the most vulnerable communities or regions experience the most exposure to climate impacts, are sensitive to climate impacts and have the weakest capacity to respond and recover (de Sherbinin, 2014). However, even within similar regions, exposure to climatic stressors, the sensitivity of populations to climatic stressors and capacities to adapt are spatially differentiated (de Sherbinin et al., 2015) such that a combination of these factors yields different vulnerability patterns. In addition, Brooks et al. (2005) notes that vulnerability is context specific and that what makes one community/region vulnerable may be different in another community/region close by. Therefore, understanding a region's vulnerability is a crucial first step before targeting adaptation assistance (Preston et al., 2011; de Sherbinin, 2014). In this regard, a vulnerability assessment was conducted to determine vulnerability of communities in Kitui County prior to implementing adaptation assistance for the communities. The study also investigated the coping strategies employed by these communities.

\section{Methodology}

\subsection{Study Area}

The study was carried out in Kitui County (Figure 1), which has an elevation ranging from $400 \mathrm{~m}$ to $1830 \mathrm{~m}$ above sea level (Jaetzold et al., 2006). The County 


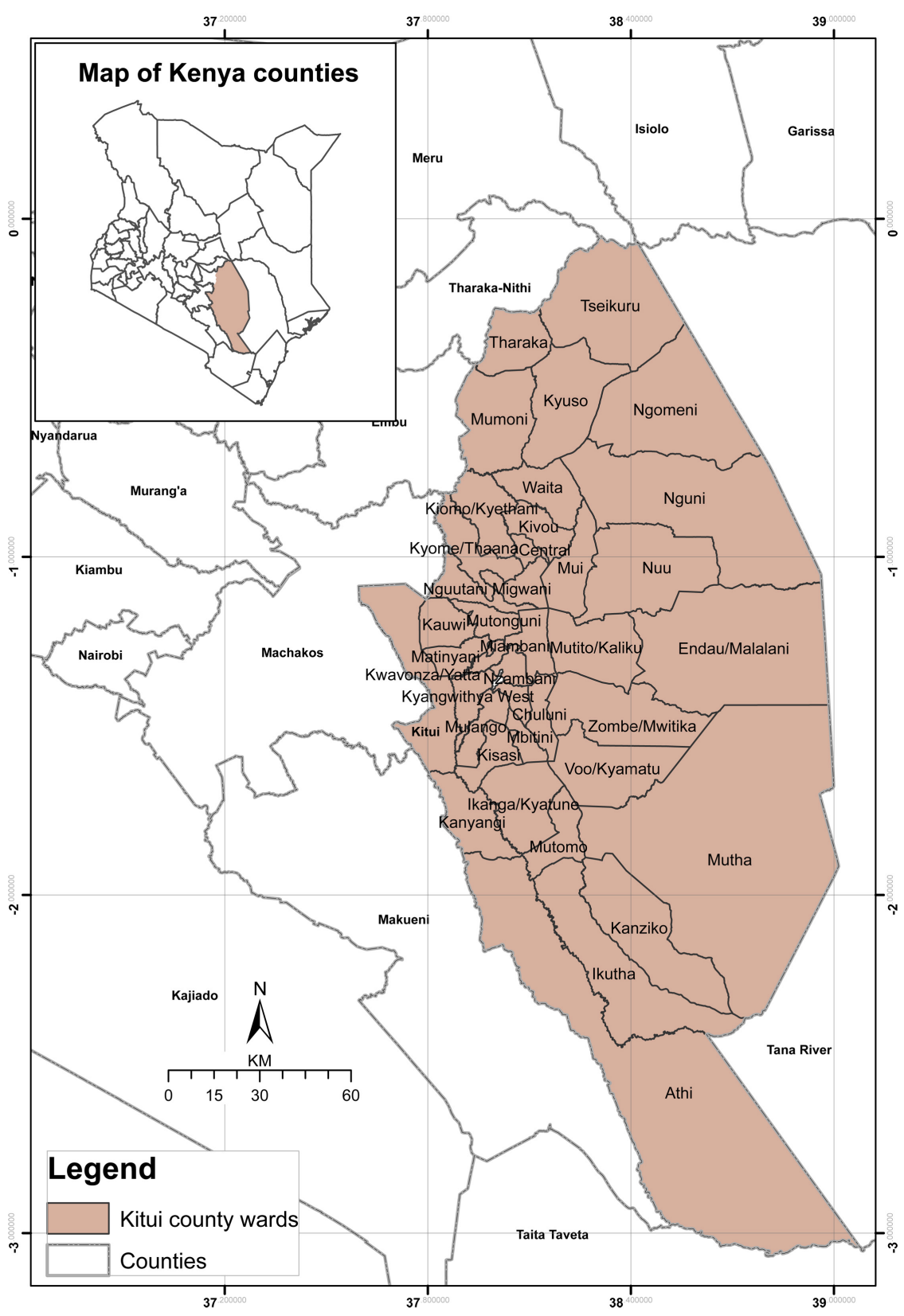

Figure 1. Map of Kitui County.

receives rainfall twice in a year, which varies from $500 \mathrm{~mm}$ to $1050 \mathrm{~mm}$. Annual mean minimum temperature ranges from $22^{\circ} \mathrm{C}$ to $28^{\circ} \mathrm{C}$ while annual mean maximum temperature ranges from $28^{\circ} \mathrm{C}$ to $32^{\circ} \mathrm{C}$. The County population is estimated at 1,012,709 (ROK, 2009).

\subsection{Vulnerability Assessment}

Various conceptual understandings of climate change vulnerability exist with little or no consensus on how to measure or map vulnerability (Preston et al., 2011). Some authors even argue that it is difficult to quantify vulnerability (Hinkel, 2011; Birkmann \& Wisner, 2006). However, several approaches have 
been employed to measure climate change vulnerability (Coulibaly et al., 2015). Guided by the IPCC conceptual framework of vulnerability, this study chose to use the indicator approach to vulnerability assessment. This approach results into a composite vulnerability index (which can be mapped into a vulnerability map) constructed from aggregated component indicators for each vulnerability component: exposure, sensitivity and adaptive capacity (Parry et al., 2007).

Following the existing vulnerability analysis literature that have used a similar approach (Cutter et al., 2003; O’Brien et al., 2004; Moss et al., 2001; Adger, 1999; Nkondze et al., 2013), the starting point was a thorough search for suitable high-resolution indicator datasets to represent each of the three vulnerability categories (exposure, sensitivity and adaptive capacity). These proxy indicators were selected in the context of smallholder farming, which is the main livelihood system of the majority of the population in Kitui County. The study focused on mapping the population's general vulnerability instead of mapping separate vulnerability components for the communities such as vulnerability on a population sub-group, or on an individual sector for example, water or agriculture. The list of indicators and their sources for each vulnerability component are shown in Table 1. In reference to other vulnerability mapping studies, indicators were selected based on representativeness to the vulnerability component in question, data availability as well as data quality.

The indicator data were first converted into percentiles ranging from 0 to 100 . A few indicators were winsorized to a maximum value and all values above this maximum were set to this maximum. For instance, minutes taken to access a market were winsorized to a maximum of three hours such that anything greater than three hours had the least adaptive capacity or highest vulnerability score (100). In a few other cases, inversion was done for indicators whose high values corresponded to low vulnerability and vice-versa (e.g. average annual precipitation, access to water, soil organic carbon and female literacy) so that high and low values would represent high and low vulnerability respectively across all indicators in similarity to de Sherbinin (2013) and Baptista (2014). This meant that adaptive capacity changes to lack of adaptive capacity in order to retain a standard meaning across indicators, such that high values corresponded to high vulnerability and vice-versa.

The raw data had different units of measurements for example millimetres for rainfall, degrees Celsius for temperature, minutes for travel time to markets, and $\%$ for poverty index. It was therefore important to overcome this incommensurability before aggregating them. In this regard, an attempt was made to normalize each data layer into a unit-less scale ranging from 0 - 100, from the least vulnerable to the highest vulnerable. The indicators were then averaged to produce component maps for exposure, sensitivity and adaptive capacity, an approach that de Sherbinin (2014) terms as additive approach to index construction. Finally, the three components were averaged together to create an overall vulnerability map. The resulting vulnerability map provided an indication of 
Table 1. List of the used indicators representing each vulnerability component.

\begin{tabular}{|c|c|c|c|}
\hline $\begin{array}{l}\text { Vulnerability } \\
\text { Component }\end{array}$ & Indicator & Indicator Variable & Data Source \\
\hline \multirow{5}{*}{ Exposure } & \multirow{3}{*}{$\begin{array}{l}\text { Precipitation } \\
\text { change }\end{array}$} & Long term average & $\begin{array}{l}\text { CHIRPS enhanced } \\
\text { precipitation, 1983-2016 }\end{array}$ \\
\hline & & Long term trend & $\begin{array}{l}\text { CHIRPS enhanced } \\
\text { precipitation, 1983-2016 }\end{array}$ \\
\hline & & $\begin{array}{l}\text { Long-term coefficient } \\
\text { of variation }\end{array}$ & $\begin{array}{l}\text { CHIRPS enhanced } \\
\text { precipitation, 1983-2016 }\end{array}$ \\
\hline & \multirow{2}{*}{$\begin{array}{l}\text { Temperature } \\
\text { change }\end{array}$} & Long term average & $\begin{array}{l}\text { CHIRPS enhanced } \\
\text { precipitation, 1983-2016 }\end{array}$ \\
\hline & & Long term trend & $\begin{array}{l}\text { CHIRPS enhanced } \\
\text { precipitation, 1983-2016 }\end{array}$ \\
\hline \multirow{5}{*}{ Sensitivity } & Poverty & Poverty index (\%) & $\begin{array}{l}\text { Kenya National Bureau of } \\
\text { Statistics (KNBS), } 2016\end{array}$ \\
\hline & $\begin{array}{l}\text { Malaria } \\
\text { susceptibility }\end{array}$ & $\begin{array}{l}\text { Malaria susceptibility } \\
\text { index }\end{array}$ & Malaria Atlas Project, 2010 \\
\hline & Soil health & $\begin{array}{l}\text { Soil organic carbon } \\
\text { stock }\end{array}$ & FAO-ISRIC Soil Grids, 2017 \\
\hline & Population & Population count & KNBS, 2010 \\
\hline & Housing & House wall type index & KNBS, 2013 \\
\hline \multirow{3}{*}{$\begin{array}{l}\text { Adaptive } \\
\text { capacity }\end{array}$} & Water access & $\begin{array}{l}\text { Access to safe } \\
\text { drinking water }\end{array}$ & KNBS, 2015 \\
\hline & Markets & $\begin{array}{l}\text { Access to market } \\
\text { services (travel time) }\end{array}$ & KNBS, 2015 \\
\hline & Literacy level & Female literacy & KNBS, 2013 \\
\hline
\end{tabular}

how multiple indicators interact to produce an aggregated vulnerability index. In other words, the analysis yielded a single index from multiple indicators. R statistical package was employed to do data transformations after which the transformed data were exported for map production in ArcGIS.

\subsection{Identification of Climate Risk Coping Strategies}

Focus group discussions (FGDs) with farmer groups in the three study sites were used to decipher the existing communities' climate risk coping strategies. The FGDs results were validated through key informant interviews as well as existing similar literature done in the area. The field study was conducted between June and August 2018. Three FGDs were undertaken with farmer groups in each study site. The main objective of the FGDs was to get insights into the existing climate risk coping strategies among the smallholder farmer communities in the study sites.

\section{Results and Discussions}

Results for the three vulnerability components are presented first and then the 
overall vulnerability of communities to climate risks. The individual component maps display the vulnerability profile of the area in terms of how each contributes to the overall vulnerability. These component maps enable the identification of areas with relatively high scores for each component. Vulnerability classes of 0 20, 20 - 40, $41-60,61-80$ and $81-100$ were used across the maps representing lowest, low, medium, high and highest vulnerability respectively to show severity of the component being measured. As indicated earlier some indicators where high values were associated with low vulnerability were inverted, for instance access to water, female literacy and access to markets. Due to this inversion "lowest lack of adaptive capacity" is interpreted as "highest adaptive capacity" and "highest lack of adaptive capacity" is interpreted as "lowest adaptive capacity". This inversion was necessary so that "lowest" class across all the component maps means lowest scores of vulnerability and "highest" class means highest scores of vulnerabilities. This also applies to the overall vulnerability map.

\subsection{Exposure Index}

The exposure index (Figure 2) was composed of annual average precipitation, trend in annual average precipitation, coefficient of variation in annual average precipitation, annual mean temperature and trend in annual mean temperature. Figure 2 indicates highest exposure in the eastern parts of the County while lowest to low exposure are in the western and central parts. As would be expected this pattern of exposure component influences the livelihood systems of the communities. The eastern parts of the County (where exposure score is the highest) practice marginal mixed farming while western parts and a small adjacent part of the central part (where exposure scores range from lowest to low respectively) practice better mixed farming comparatively.

\subsection{Graphical Representation of the Climatic Parameters Used in Computing the Exposure Index}

In addition to the exposure index map, we used histograms (Figure 3) to show the distribution of data across the entire study area represented by the number (frequency) of $1 \mathrm{~km}^{2}$ pixels. Most of the study area has experienced an increase in annual mean temperature (a), with most of the areas observed to have increases of $>1^{\circ} \mathrm{C}$. On average, the study area is hot as it falls within the ASAL classification (b) and receives low annual rainfall (c). Our analysis also revealed that annual average rainfall in the area is on a decreasing trend (d), with most parts of the county having decreases of $>50 \mathrm{~mm}$ and experiences high variability $(\mathrm{CV}>30)$ in annual average rainfall (e).

\subsection{Sensitivity Index}

The sensitivity index (Figure 4) was composed of poverty index, malaria susceptibility, soil organic carbon, population count, and percentage of poor wall type. The sensitivity pattern reveals high sensitivity in central parts and a few areas in 


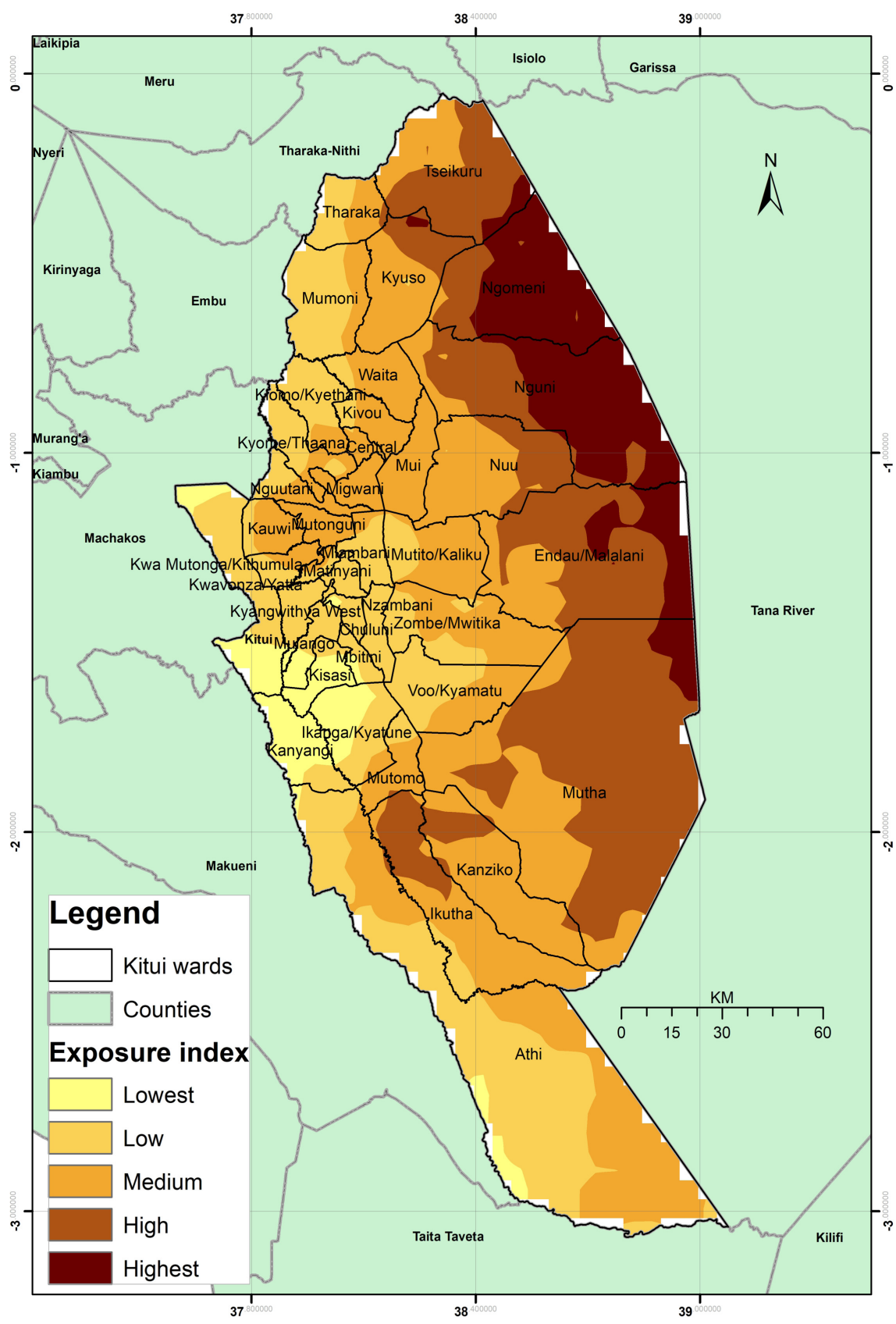

Figure 2. Exposure index.

the eastern part of the County. Much of the western parts of the County have lowest to low sensitivity.

\subsection{Lack of Adaptive Capacity Index}

The lack of adaptive capacity index (Figure 5) was composed of access to improved water sources, access to markets and female literacy. The map reveals an increasing pattern of lack of adaptive capacity with distance from the County headquarter (Kitui town) and from the next big town centre (Mwingi). Urban areas have relatively high adaptive capacity and this could be attributed partly to 


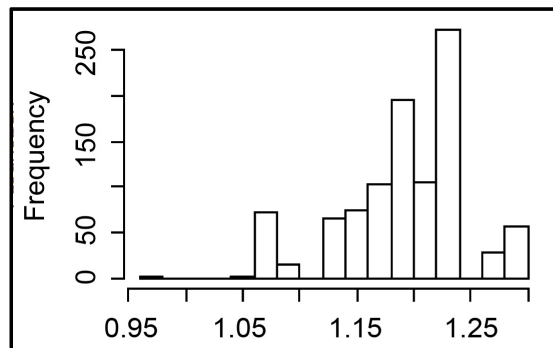

Trend in annual average temperature ${ }^{\circ} \mathrm{C}$

(a)

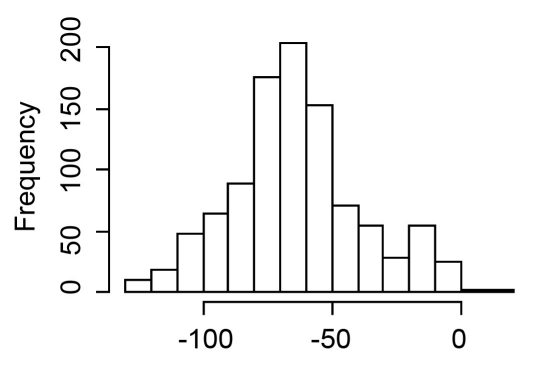

Trend in annual average rainfall $(\mathrm{mm})$

(d)

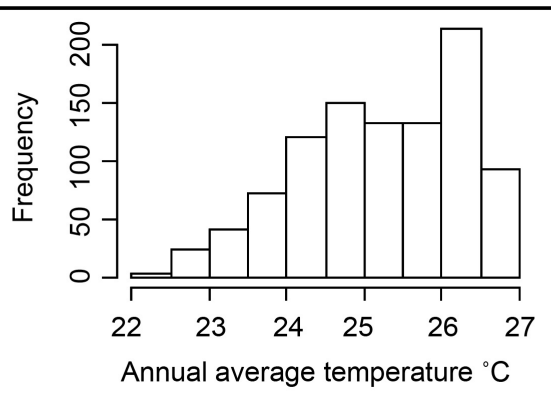

(b)

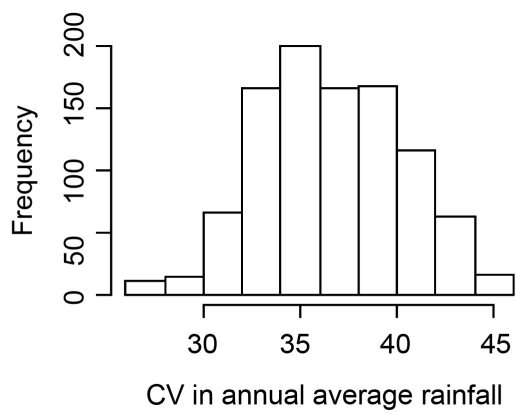

(e)

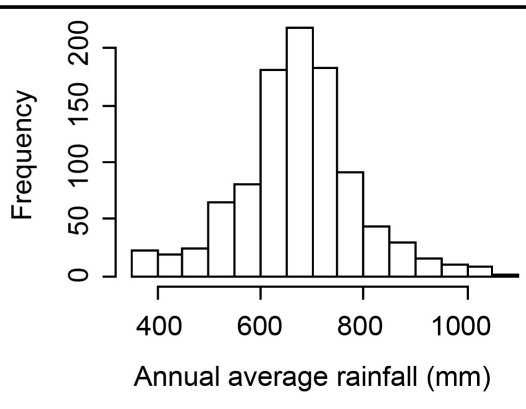

(c)

Figure 3. Graphical representation of climatic parameters used in computing the exposure index.

accessibility of safe water and to the density of road infrastructure in the vicinity of these locations and consequently market accessibility. Locations with low adaptive capacity are in the drier lowlands of Tseikuru, Ngomeni, Endau, parts of Kyuso and parts of Tharaka.

\subsection{Overall Vulnerability}

The overall vulnerability map resulted from averaging the exposure, sensitivity and adaptive capacity indices (Figure 6). Generally, as Figure 6 shows, vulnerability in Kitui County proceeds in a west-east gradient with the lowest vulnerability over western part of the County except in some areas in Kanziko, Kyamatu and Ikutha wards and highest vulnerability in the extreme eastern side of the entire County. These results are not overlay surprising in that they reflect the livelihoods systems in the County with marginal mixed farming in the eastern parts where overall vulnerability is high and a better mixed farming in the western parts where overall vulnerability is comparatively low. Also, the regions with high to highest overall vulnerability (eastern parts of the County) are also the regions with high to highest exposure and lack of adaptive capacity. These eastern parts include the drier lowlands stretching from the north (Tseikuru, Kyuso, Mwingi, Ngomeni, Nguni and Nuu), through the Yatta plateau, down to the eastern areas (Mutito and Mwitika) and southern areas (Mutomo and Ikutha). Comparatively, these areas are drier and with more erratic rainfall. They are also prone to conflict along the border with Tana River County (ROK, 2005), which enhances their sensitivity to climate risks and lack of adaptive capacity to cope 


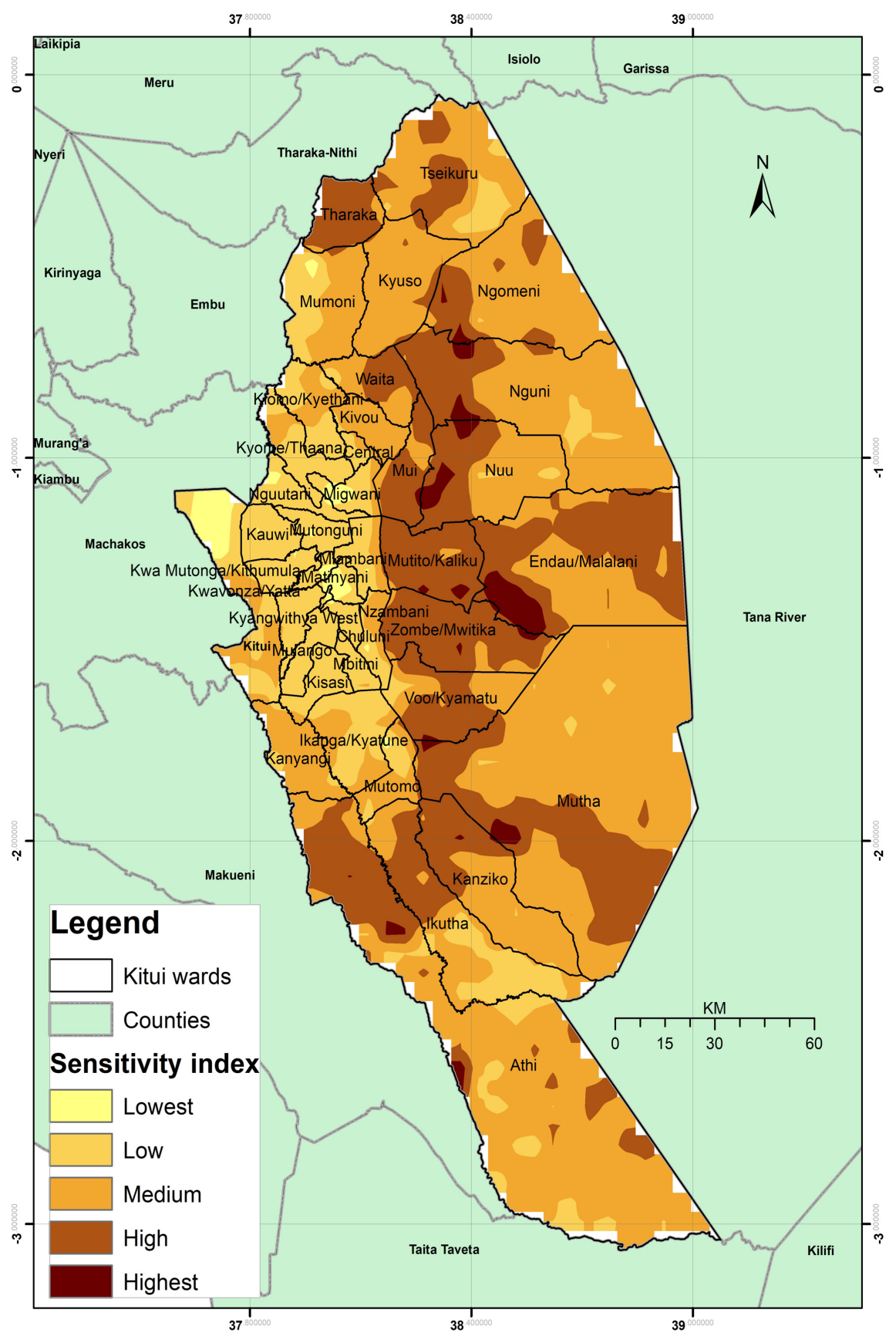

Figure 4. Sensitivity index.

with the risks.

Measuring and mapping vulnerability have been highlighted as a first step for supporting adaptation decision-making (Preston et al., 2011).

\subsection{Coping Strategies Adopted by Farmers in Response to Climate Risks}

In line with the vulnerability assessment results, FGDs with the different farmer groups in the study sites revealed that farmers are vulnerable to climate risks, 


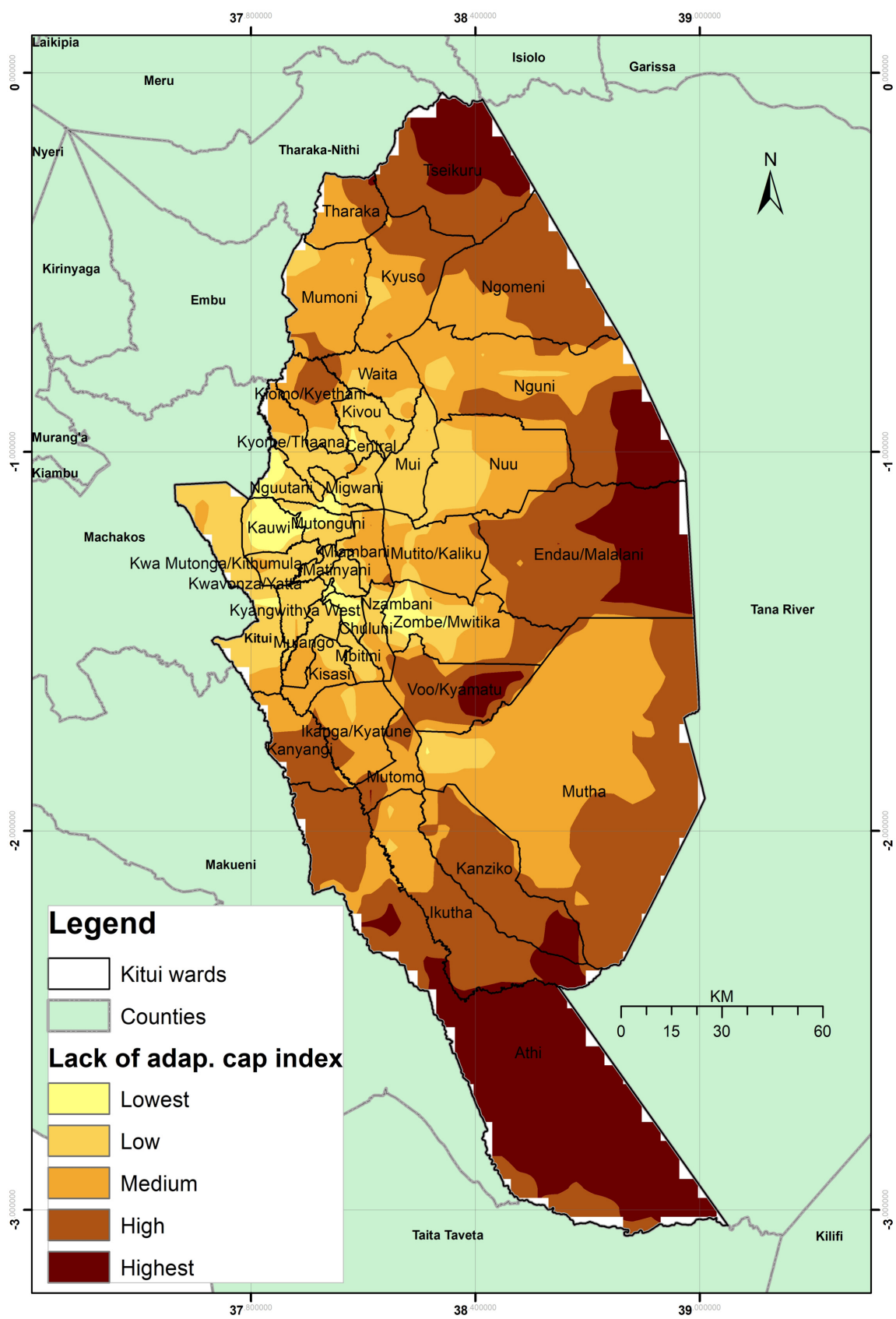

Figure 5. Lack of adaptive capacity.

which they mainly experience through seasonal rainfall variability, decreasing rainfall, increasing temperatures, increasing dry spells during rainfall seasons and increasing return period and severity of droughts. In response to these risks they have adopted various coping strategies to help them reduce their vulnerability. The discussants indicated that they sell off some livestock in order to reduce the heard number during dry seasons when pasture is inadequate. They also undertake water harvesting during a good rainfall season and store it for use during lean periods. Planting diversified agricultural crop varieties and types instead of concentrating only on one variety/type was also another coping strategy, 


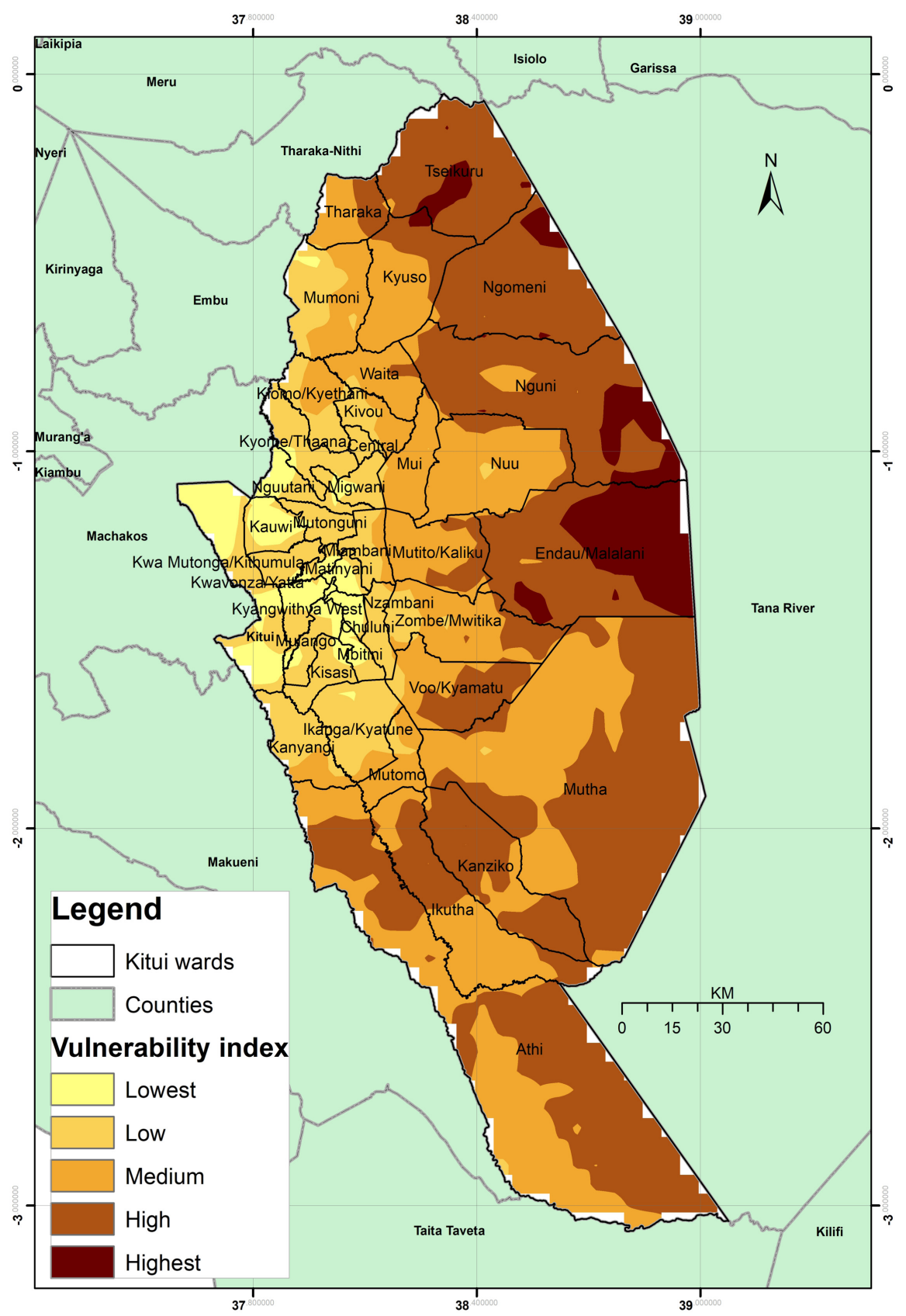

Figure 6. Overall vulnerability index.

which they said helped them reduce agricultural losses. Another coping strategy as reported was reducing acreage under cultivation to reduce cost of farm inputs and losses in case of an impending poor rainfall season. Farmers also said they plant early maturing crops such as hybrid maize and bean varieties and cowpeas since some seasons have tended to be shorter than usual.

In addition, farmers have adopted soil conservation techniques, some traditional and others introduced to them through a Non-Governmental Organizations (ActionAid) such as use of Zai pits to conserve moisture, harvest surface runoff and restore soil fertility. Staggering of planting dates is another coping 
strategy in which farmers said they plant some sections of the farm before the onset of the rains and other sections after the onset of rains to reduce loss of seeds and the need to re-plant the whole farm again. The farmers also invest in small businesses and seek casual jobs especially during drought periods in order to meet household needs. Key informant interviews validated the information from the FGDs and added that farmers also undertake animal manure, fertilizer and pesticides application to increase agricultural production in the thick of climate variability. Generally, these findings were in consonance with those of other authors who have done similar research in the study area for instance Okumu (2013), Ndambiri et al. (2012) and Mutunga et al. (2017).

\section{Summary and Conclusion}

The results have shown that vulnerability and its components present high levels of spatial differences, which underscores the usefulness of vulnerability mapping. An additive approach was used where indicators for each vulnerability component were aggregated into a single index for each component (coming from many indicators to a single indicator). This yielded an exposure index, a sensitivity index and a lack of adaptive capacity index. These three indices were then aggregated to produce the overall vulnerability map. The analysis was based on the assumptions regarding vulnerability mapping (Fussel, 2009; Eakin \& Luers, 2006), which assumes that there exists linearity between each vulnerability component and its indicators. It was also assumed that high scores in one index compensate low scores in other indices though this might not always be the case.

Exposure component map shows highest exposure in the entire western parts of the County. Sensitivity component map indicates lowest sensitivity over eastern parts, medium sensitivity over western parts except in Endau and highest sensitivity over the central parts of the County. Adaptive capacity results indicate lowest lack of adaptive capacity over western and much of central parts except Kyamatu and medium to highest lack of adaptive capacity over the entire eastern parts of the County. On the other hand, overall vulnerability results as shown on the vulnerability map present a west to east gradient with the lowest vulnerability in western parts except a few areas and highest vulnerability over the extreme eastern parts of the County. Farmers have however, devised local coping strategies to address this vulnerability ranging from reducing number of on farm livestock during droughts, conserving soils, diversifying crop types and varieties, water harvesting, reducing cultivation acreage, planting at staggered dates, planting early maturing crops, planting drought resistant crops, diversifying farm income through small businesses, use of animal manure, use of fertilizer and use of pesticides.

In conclusion, the individual component maps give an indication of the factors that contribute to vulnerability of every area, which informs what adaptation befits where. It is evident from the results that Kitui County communities are vulnerable to climate change risks with differentiated vulnerability scores 
(lowest to highest). On the other hand, increasing climate variability and frequency as well as severity of extreme events have rendered the current coping strategies inadequate, which have caused the farmers to remain vulnerable.

\section{Recommendations}

The differentiated patterns of vulnerability emphasize that vulnerability is context specific and hence context specific responses and adaptation strategies are required at local levels. In line with this, it is imperative that context specific adaptation solutions are sought to address vulnerability. An example of this is a local climate information and services framework that can reduce climate change vulnerability through informing smallholder farm level management and thus yield adaptation benefits over the long run. However, the different principal livelihoods in the County (mixed farming and marginal mixed farming) should be put into consideration during formulation of all adaptation solutions. This is because an adaptation solution that befits communities in one principal livelihood may not befit others practicing a different livelihood. Lastly, communities' coping strategies against the present-day climate risk vulnerability should be strengthened as a prime means of facilitating adaptation to climate change over longer timescales. This is in cognizant to the fact that factors that shape day to day coping capacity will complement factors that will shape capacity to adapt in the long term.

\section{Acknowledgements}

We would like to thank the anonymous reviewers for their helpful comments and suggestions.

\section{Conflicts of Interest}

The authors declare no conflicts of interest regarding the publication of this paper.

\section{References}

Adger, W. N. (1999). Social Vulnerability to Climate Change and Extremes in Coastal Vietnam. World Development, 27, 249-269. https://doi.org/10.1016/S0305-750X(98)00136-3

Baptista, S. R. (2014). Design and Use of Composite Indices in Assessments of Climate Change Vulnerability and Resilience. New York: The Earth Institute, Columbia University.

Birkmann, J., \& Wisner, B. (2006). Measuring the Un-Measurable: The Challenge of Vulnerability. UNU-EHS Source, No. 5, Bonn: United Nations University, Environment and Human Security.

Brooks, N., Adger, W. N., \& Kelly, P. M. (2005). The Determinants of Vulnerability and Adaptive Capacity at the National Level and the Implications for Adaptation. Global Environmental Change, 15, 151-162. https://doi.org/10.1016/j.gloenvcha.2004.12.006

Coulibaly, J. Y., Mbow, C., Sileshi, G. W., Beedy, T., Kundhlande, G., \& Musau, J. (2015). 
Mapping Vulnerability to Climate Change in Malawi: Spatial and Social Differentiation in the Shire River Basin. American Journal of Climate Change, 4, 282. https://doi.org/10.4236/ajcc.2015.43023

Cutter, S. L., Boruff, B. J., \& Shirley, W. L. (2003). Social Vulnerability to Environmental Hazards. Social Science Quarterly, 84, 242-261. https://doi.org/10.1111/1540-6237.8402002

de Sherbinin, A. (2013). Climate Change Hotspots Mapping: What Have We Learned? Climatic Change, 123, 23-37. https://doi.org/10.1007/s10584-013-0900-7

de Sherbinin, A. (2014). Mapping the Unmeasurable? Spatial Analysis of Vulnerability to Climate Change and Climate Variability. PhD Thesis, Enschede: University of Twente.

de Sherbinin, A., Chai-Onn, T., Jaiteh, M., Mara, V., Pistolesi, L., Schnarr, E., \& Trzaska, S. (2015). Data Integration for Climate Vulnerability Mapping in West Africa. ISPRS International Journal of Geo-Information, 4, 2561-2582. https://doi.org/10.3390/ijgi4042561

Eakin, H., \& Luers, A. L. (2006). Assessing the Vulnerability of Social-Environmental Systems. Annual Review of Environment and Resources, 31, 365-394. https://doi.org/10.1146/annurev.energy.30.050504.144352

Fussel, H. (2009). Review and Quantitative Analysis of Indices of Climate Change Exposure, Adaptive Capacity, Sensitivity and Impacts. In World Bank Development Report 2010: Development and Climate Change (pp. 75-82). Potsdam: World Bank.

Hinkel, J. (2011). "Indicators of Vulnerability and Adaptive Capacity": Towards a Clarification of the Science-Policy Interface. Global Environmental Change, 21, 198-208. https://doi.org/10.1016/j.gloenvcha.2010.08.002

IPCC (2001). Summary for Policymakers. Climate Change 2001: Impacts, Adaptation, and Vulnerability: A Report of Working Group II of the IPCC. Geneva: IPCC.

IPCC (2014). Climate Change 2014: Impacts, Adaptation, and Vulnerability. Part A: Global and Sectoral Aspects. In C. B. Field, V. R. Barros, D. J. Dokken, K. J. Mach, M. D. Mastrandrea, T. E. Bilir, M. Chatterjee, K. L. Ebi, Y. O. Estrada, R. C. Genova, B. Girma, E. S. Kissel, A. N. Levy, S. MacCracken, P. R. Mastrandrea, \& L. L. White (Eds.), Contribution of Working Group II to the Fifth Assessment Report of the Intergovernmental Panel on Climate Change (1132 p.). Cambridge: Cambridge University Press.

Jaetzold, R., Schmidt, H., Hornetz, B., \& Shisanya, C. (2006). Farm Management Handbook of Kenya (Vol. 2/C1). Nairobi: Ministry of Agriculture.

Mechler, R., \& Bouwer, L. M. (2015). Understanding Trends and Projections of Disaster Losses and Climate Change: Is Vulnerability the Missing Link? Climatic Change, 133, 23-35. https://doi.org/10.1007/s10584-014-1141-0

Moser, C. O. N. (1998). The Asset Vulnerability Framework: Reassessing Urban Poverty Reduction Strategies. World Development, 26, 1-19. https://doi.org/10.1016/S0305-750X(97)10015-8

Moss, R. H., Brenkert, A. L., \& Malone, E. L. (2001). Vulnerability to Climate Change. A Quantitative Approach. Report No. PNNL-SA-33642, Washington DC: Pacific Northwest National Laboratory. http://www.ntis.gov

Mutunga, E. J., Ndungu, C. K., \& Muendo, P. (2017). Smallholder Farmers' Perceptions and Adaptations to Climate Change and Variability in Kitui County, Kenya. Journal of Earth Science and Climatic Change, 8, 389.

Ndambiri, H., Ritho, C., Mbogoh, S., Ng'anga, S., Muirur, E. et al. (2012). Assessment of Farmers' Adaptation to Effects of Climate Change in Kenya. Journal of Economics and Sustainable Development, 4, 16-20. 
Nkondze, M. S., Masuku, M. B., \& Manyatsi, A. (2013). Factors Affecting Households Vulnerability to Climate Change in Swaziland: A Case of Mpolonjeni Area Development Programme (ADP). Journal of Agricultural Science, 5, 108-122. https://doi.org/10.5539/jas.v5n10p108

O’Brien, K., Leichenko, R., Kelkar, U., Venema, H., Aandahl, G., Tompkins, H. et al. (2004). Mapping Vulnerability to Multiple Stressors: Climate Change and Globalization in India. Global Environmental Change, 14, 303-313. https://doi.org/10.1016/j.gloenvcha.2004.01.001

Okumu, O. F. (2013). Small-Scale Farmers' Perceptions and Adaptation Measures to Climate Change in Kitui County, Kenya.

Parry, M. L., Canziani, O. F., \& Palutikof, J. P. (2007). Technical Summary. In M. L. Parry, O. F. Canziani, J. P. Palutikof, P. J. van der Linden, \& C. E. Hanson (Eds.), Climate Change 2007: Impacts, Adaptation and Vulnerability (pp. 23-78). Cambridge: Cambridge University Press.

Preston, B. L., Yuen, E. J., \& Westaway, R. M. (2011). Putting Vulnerability to Climate Change on the Map: A Review of Approaches, Benefits, and Risks. Sustainability Science, 6, 177-202. https://doi.org/10.1007/s11625-011-0129-1

Republic of Kenya ROK (2005). Kitui District Strategic Plan 2005-2010 for Implementation of National Population Policy for Sustainable Development. Nairobi: National Coordinating Agency for Population and Development.

Republic of Kenya ROK (2009). National Population and Housing Census Report. Nairobi: Kenya National Bureau of Statistics.

Shirley, W. L., Boruff, B. J., \& Cutter, S. L. (2012). Social Vulnerability to Environmental Hazards. In Hazards Vulnerability and Environmental Justice (pp. 143-160). Abingdon-on-Thames: Routledge. 